\title{
Numerical Analysis of a Write Head for High-Density Perpendicular Magnetic Recording
}

\author{
K. Fudano,***, Y. Suzuki ${ }^{* * * *}$, and Y. Nakamura* \\ *Research Institute of Electrical Communication, Tohoku Univ., Katahira 2-1-1, Aoba-ku, Sendai 980-8577, Japan \\ ${ }^{*}$ NEC Software Tohoku, Ltd., 1-10-23 Ichiban-cho, Aoba-ku, Sendai 980-0811, Japan \\ ${ }^{* * *}$ Central Research Lab., Hitachi, Ltd., 1-280 Higashi-Koigakubo, Kokubunji, Tokyo 185-8501, Japan
}

A strong and sharp write-head magnetic field distribution is necessary in order to achieve higher density in perpendicular magnetic recording. The magnetic field of a head medium model was calculated by using a finite element method (FEM) simulator. In studying the head-medium interaction, an FEM simulator was combined with a magnetizing reversal model to realize self-consistent calculation. The magnetic circuit formed by a single-pole head and the soft-magnetic underlayer of a double-layered medium produces an efficiently strong magnetic field. By taking account of the head-medium interaction, a stronger and sharper head field distribution was produced.

Key words: perpendicular magnetic recording, FEM simulation, cusp coil, head-medium interaction, self-consistent calculation, single pole tip, soft-magnetic underlayer, curling mode

\section{垂直磁気記録の高密度化のための記録ヘッド構造の数値解析}

札野欽也*,** 鈴木良夫*,*** 中村慶久*

*東北大学 電気通信研究所, 仙台市青葉区片平 2-1-1（干980-8577）

*** N E Cソフトウェア東北（株），仙台市青葉区一番町 1-10-23（－９80-0811）

*** (株) 日立製作所 中央研究所，国分寺市東恋ヶ窪 1-280（テ185-8501）

1. はじめに

垂直磁気記録の高密度化のためには，結晶粒が微細化されかつ 高い磁気異方性を持つ記録媒体と，それに対応した強く急峻な勾 配の記録磁界を発生する記録へッドが必要である。そのためには, ヘッド・媒体を全て含んだ記録過程モデルを構築し，ヘッド設計 およひ媒体設計のための指針を示すことが有効である. 我々は, 垂直磁気記録用単磁極へッド(SPTヘッド)をモデル化し, 三次元有 限要素法を用いてシミュレーションを行うことにより，記録磁界 を高めるために必要な要因についての検討を行っている1),2)。ま た，ヘッド・メディア間の相互作用を取り入れたセルフコンシス テント計算 3)を用いることにより，定量的に精度の高い記録過程 を再現できることが知られている4).

本論文では，特に主磁極・リターンヨークの磁路構造と記録磁 界分布との関係について，解析を行った. 寸なわち，へッドの磁 路構造や，主磁極に対するコイルの設置位置を種々に変化させた モデルについて解析を行い，高記録磁界の発生要因の検討を行つ た．また今回使用したモデルをもとに，実用的なヘッドの 1 つと して提案されているカスプコイル励磁型単磁極へッド 5)の磁界分 布を調べることにより，へッド磁路が高記録磁界の発生に与える 影響を確認した．さらに記録層の磁化の計算により，ヘッド・媒 体相互作用 3)を考慮したときの，記録層が在ることの記録磁界に 対する影響についても検討を行った。

\section{2. 計算方法}

\section{1 記録ヘッドの有限要素解析}

小さな印加電流で効率よく記録磁界を発生させるためには，磁 気回路の特定の部分でヘッド材料が磁気飽和することを避け，へ ッド磁極先端に磁束が到達するような構造としなければならない.

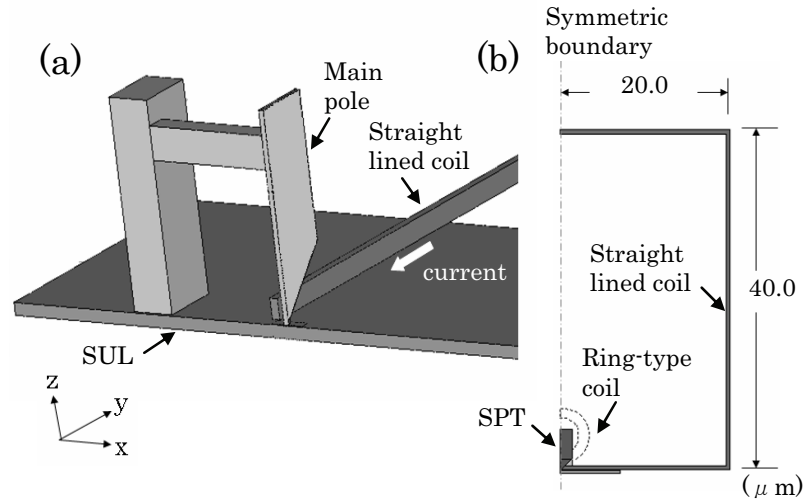

Fig. 1 Calculation model in the case of a straight line current: (a) upper view, (b) front view.

(a)

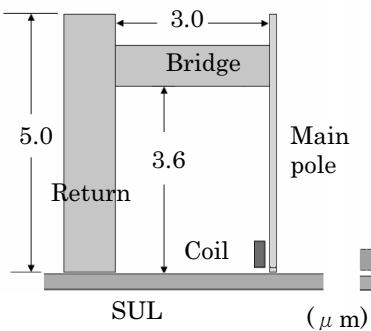

(c) bymmetric

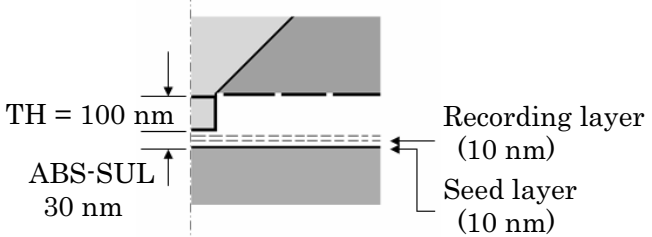

Fig. 2 (a) Side view, (b) front view, and (c) enlarged view of a single-pole-tip write head and the soft underlayer of the medium. 
我々はコイルとヘッド磁極との位置関係の効果を検討するために, トラック幅方向に無限に長い直線状のコイルを用いてシミュレー ションを行った.

Fig.1 に，解析に用いたヘッドのモデルを示す．Fig.1(a)は俯瞰 図, Fig.1(b)はへッド進行方向からの図である. 図のように, 主磁 極中心軸を通りヘッド厚さ方向に平行な平面を対称境界とし，へ ッド全体に対して半分の領域を解析対象としている. また，以下 で「直線状コイル」と呼ぶものは，主磁極先端近くで直線的であ り，磁極よりも十分離れたところを巻いて戻ってくる長方形の環 状コイルをさす、ヘッド側面から見たときのコイルの位置条件を 特定することができるようにするため, コイルをクロストラック 方向に直線状に配置した. Fig.2 において, (a)は,ヘッドの側面図,

(b)は正面図 (両対称領域を含む)，(c)は主磁極先端部分を拡大した 正面図である.

主磁極形状は, 記録密度 $300 \mathrm{~Gb} / \mathrm{in}^{2}$ を想定し, Table 1 に示すよ うなものとした. 記録トラック幅は $120 \mathrm{~nm}$, 厚さは $120 \mathrm{~nm}$ であ る. また，スロートハイト $100 \mathrm{~nm}$ とし，45のテーパー部を 設け, 全体として幅 $4.0 \mu \mathrm{m}$, 高さ $5.0 \mu \mathrm{m}$ となる. またブリッ ジは, 幅 $1.0 \mu \mathrm{m}$, 厚さ $3.0 \mu \mathrm{m}$, 高さ $0.8 \mu \mathrm{m}$ とし, 主磁極先 端から $3.6 \mu \mathrm{m}$ の深さの位置に設置した. リターンヨークは, 幅 $4.0 \mu \mathrm{m}$, 厚さ $1.0 \mu \mathrm{m}$, 高さ $5.0 \mu \mathrm{m}$ とした. ヘッドは, 初透 磁率を 2000 , 飽和磁束密度を $24 \mathrm{kG}$ とし, B-H 曲線を $\arctan$ 関 数で近似している.

記録媒体は, 記録層(厚さ $10 \mathrm{~nm})$, 非磁生下地層(厚さ $10 \mathrm{~nm}$ ), 軟磁性裏打ち層（SUL）(厚さ $300 \mathrm{~nm}$ )よりなる (Fig.2(c)). 主磁 極先端と SUL 表面間の距離は, $30 \mathrm{~nm}$ とした. 後述する $\mathbf{3 . 4}$ に記 す検討以外では，記録層の磁化は考慮せずに計算した．SULは初 透磁率を 2000 , 飽和磁束密度を $20 \mathrm{kG}$ とした. コイルは断面形状 が $200 \mathrm{~nm} \times 500 \mathrm{~nm}$ の矩形となるようにし，Fig.2(a)に示すよう に, 深さ $100 \mathrm{~nm}$ にて, 主磁極先端より $100 \mathrm{~nm}$ 離して設置した.

三次元有限要素解析プログラムは, JMAG-Studio 8.2 ((株)日本 総研ソリューションズの製品）6)を用いた.

\section{2 ヘッド・媒体相互作用を考慮した計算の方法}

3.4 では, 前項で記述したヘッドモデルに加えて記録層の磁化を 置いて計算を行った 7). 記録層の磁化反転は, Curling モデル 8),9) により非一斉磁化反転の効果を実効的に取り込んで, 記録媒体の ヒステリシスループを復元するものである. 電磁界の有限要素法 計算にこの記録層の磁化反転モデルを組み込みセルフコンシステ ントに解くことにより，ヘッド・媒体相互作用の影響を取り入れ ることが可能となった.

記録層の物性值を, Table 2 に示す.一軸異方性を有する粒子と 仮定し，容易軸を膜面垂直方向とした。粒子間の交換相互作用は ゼロとした. また, SUL 無しの記録層の垂直方向磁化曲線を Fig.3 に示寸. Fig.4 は, ヘッド媒体相互作用の計算を行う際の主磁極先 端と記録層のモデルである. ヘッドと記録層の磁気的スペーシン

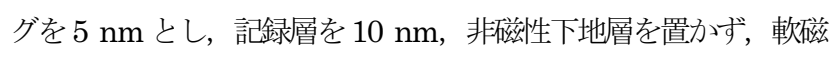
性裹打ち層 SUL は, 初透磁率を 2000 , 飽和磁束密度を $24 \mathrm{kG}$, 厚さを $300 \mathrm{~nm}$ とした.

\section{3. 結果および解析}

Table 1 Parameters of the main pole.

\begin{tabular}{|c|c|}
\hline \multicolumn{2}{|l|}{ Main pole } \\
\hline Thickness & $120 \mathrm{~nm}$ \\
\hline Track width & $120 \mathrm{~nm}$ \\
\hline Throat height & $100 \mathrm{~nm}$ \\
\hline Length & $5000 \mathrm{~nm}$ \\
\hline Saturation flux density & $24 \mathrm{kG}$ \\
\hline Initial magnetic permeability & 2000 \\
\hline
\end{tabular}

Table 2 Parameters of a recording layer.

\begin{tabular}{|lc|}
\hline Recording layer & \\
Thickness & $10 \mathrm{~nm}$ \\
Saturation magnetization & $6.3 \mathrm{kG}$ \\
Coercivity & $5 \mathrm{kOe}$ \\
Mean Hk & $15 \mathrm{kOe}$ \\
Standard deviation of Hk & $1.5 \mathrm{kOe}$ \\
Standard deviation of easy axes & 20 degrees \\
Intergranular exchange & 0.0 \\
\hline
\end{tabular}

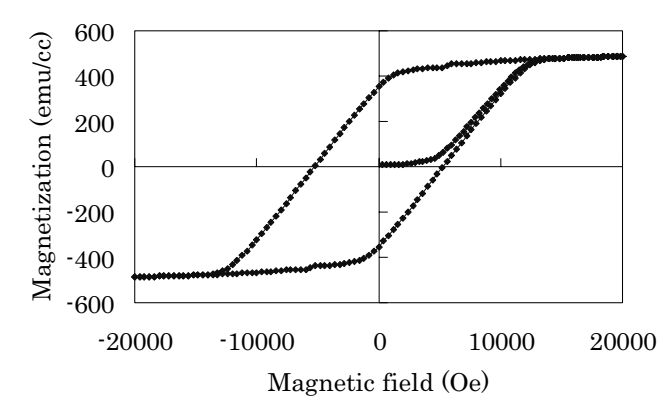

Fig. 3 M-H loop of the recording layer.

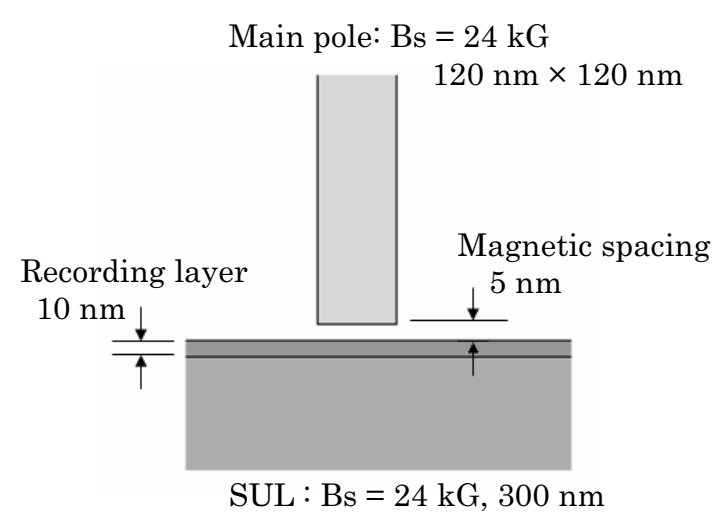

Fig. 4 Main pole and recording layer.

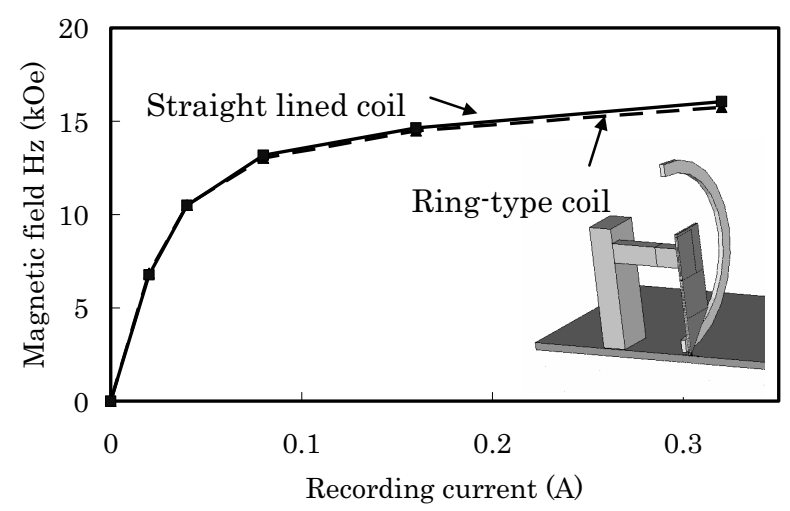

Fig. 5 Magnetic field dependence on the recording current in the case of a straight lined coil (solid line) and a ring-type coil (dotted line). 
ヘッドの磁路構造およびコイルの形状と位置が記録磁界に及ぼ す影響を調べた．まず，直線状コイルを用いることの妥当性を確 かめるために, 通常用いられている円弧型コイルを用いた場合と の比較を行った. 円弧型コイルは, 断面形状が $200 \mathrm{~nm} \times 500 \mathrm{~nm}$ の矩形となるようにし, 内径を $3.4 \mu \mathrm{m}$ とした. Fig.5 は, 直線状 コイルを用いたへッドおよび円弧型コイルを用いたへッドの，記 録へッド磁界のコイル印加電流依存性である.ここでは磁界は, ヘッド表面より $10 \mathrm{~nm}$ 離れた記録層表面のトラック中心における 磁界である，なお両者でのコイル位置は，主磁極先端に最も接近 する場所で一致している. すなわち，トラック中心の断面が重な りあうようにした. Fig.5にて, 両者の磁界がほぼ重なることから, 直線状コイルを用いてコイル位置の依存性を検討寸ることが妥当 であることが確認された。

\section{1 ヘッド内の磁路の影響}

ヘッドの戻り磁路は，主磁極の先端を効率良く励磁するための 磁気回路を, SULとともに構成する. 戻り磁路の効果を確認する ために，通常の構造のヘッドから，ブリッジ，およびリターンヨ 一クを取り去ったものについて磁界解析を行った.

Fig.6 は, 記録層表面に相当する面で主磁極中心の直下でのヘッ ド磁界の垂直 $(\mathrm{z})$ 成分の記録電流依存性である. リターンヨーク とブリッジがともにある場合は，比較的小さい電流で磁界強度が 飽和に達している. これは後にも述べるとおり, 戻り磁路と SUL で構成される磁気回路の効果により磁路内部での局所的な磁気飽 和が抑えられることと, テーパー構造による磁束の絞込みにより 主磁極先端に効率良く磁束が集中していることによる. 一方, ブ リッジ無しの場合およびブリッジとリターンヨークともに無い場 合は, 磁気回路の効果が下がり, 磁界強度が飽和に達するにはよ り大きな電流が必要となる. このように, ヘッドと SULによる閉 磁路構造を形成することにより，小さな励磁電流でヘッド先端に 強い磁界を効率良く発生させることができる，ただし戻り磁路の 構造によっては, リターンヨークから記録層に数 $\mathrm{kOe}$ 程度の磁界 が印加される場合があるので，この戻り磁界を低く抑えるような 設計が必要となる.

また，いずれの場合でも，磁界強度の飽和後も磁界が増加し続 ける. これは，コイルによる直接磁界の寄与が比較的大きいため である. コイルのみを置いた場合の磁界も Fig.6 に示寸が, 磁界強 度の飽和後に磁界が線形に増加し続ける傾きは, コイルのみの場 合の傾きとほぼ等しい.

\section{2 記録ヘッド磁界のコイル位置依存性}

次に，主磁極に対するコイルの位置を変えたときの磁界への影 響を検討した. このために, Fig.7のようにコイルを 1 から 5 まで の位置に設置した場合につき磁界計算した ${ }^{2)}$ 。また，ヘッドの戻 り磁路がある場合と無い場合との比較も行った.

ここで用いたへッドは，主磁極は前述のものに対して深さ方向 に $1.0 \mu \mathrm{m}$ 伸ばし, また主磁極の最上部から $1.0 \mu \mathrm{m}$ の幅でブリ ッジを介してリターンョークに接続している. ブリッジは, 幅 4.0 $\mu \mathrm{m}$, 厚さ $3.0 \mu \mathrm{m}$, 高さ $1.0 \mu \mathrm{m}$ とし, 主磁極先端から $5.0 \mu$ $\mathrm{m}$ の深さの位置に設置した. リターンョークは, 幅 $8.0 \mu \mathrm{m}$, 厚 さ $1.0 \mu \mathrm{m}$, 高さ $10.0 \mu \mathrm{m}$ とした.

まず, 励磁コイルの位置の違いによる, 主磁極内の磁束密度分

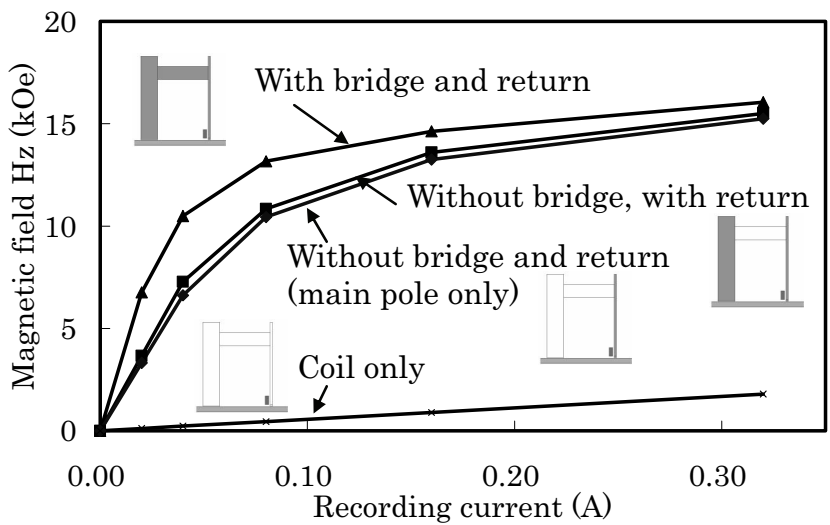

Fig. 6 Magnetic field dependence on the recording current with or without the return yoke and bridge of the head.

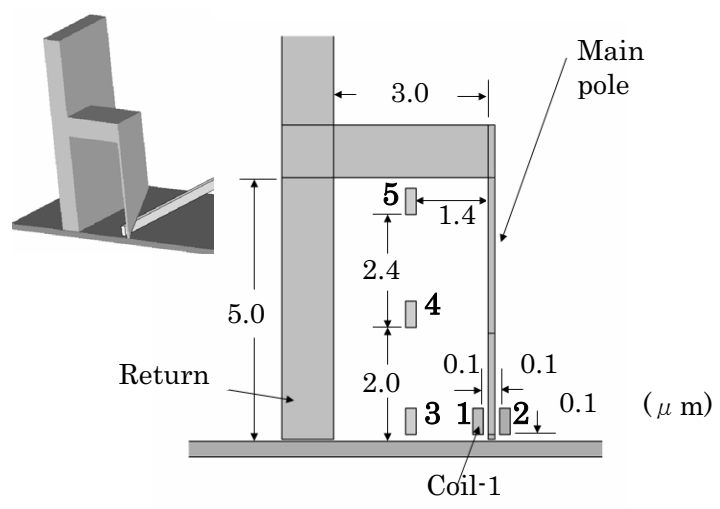

Fig. 7 Positions of the coils ( 1 to 5 , bold numbers) in the head.

(a)

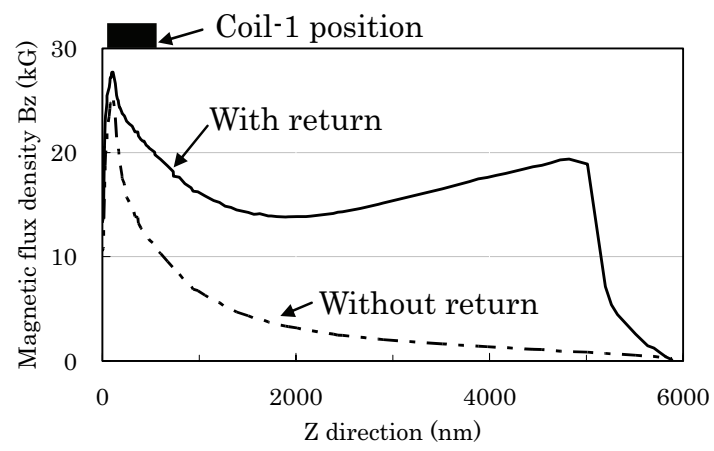

(b)

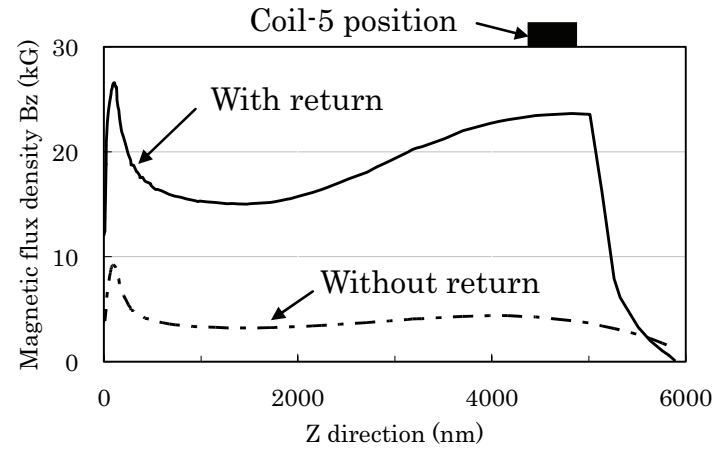

Fig. 8 Magnetic flux density in a main pole in the case of (a) coil- 1 and (b) coil- 5 , with a return yoke (solid line) and without a return yoke (dotted line). 
布の比較を行った. Fig.8(a)と Fig.8(b)は，コイルを主磁極先端に 近づけた場合（位置1）と，遠ざけた場合（位置5）について, 戻り磁路が無い場合と有る場合の主磁極内部の磁束密度分布であ る. コイル印加電流は, $0.08 \mathrm{~A}$ としている. Fig. 8 の横軸は記録層 表面からの距離であり, 主磁極の中心軸における磁束密度の垂直 成分 $B_{z}$ をプロットした. 戻り磁路の無い場合には，主磁極は，コ イルと同じ深さ位置を中心として磁化される，そのためコイル位 置 1 の場合のように主磁極先端に近くにコイルを設置した場合ほ ど, 主磁極先端の磁束密度が大きくなる. 戻り磁路の有る場合は Fig.8のとおり, 戻り磁路側から流れ込む磁束により主磁極内の磁 束密度が全体的に増大し，またコイル位置が異なっていても主磁 極内の磁束密度分布に大きな違いが無く, 主磁極先端の磁束密度 も大きい，いずれの場合でも主磁極先端部分では，磁束密度が主 磁極の飽和磁化 $4 \pi M S$ である $24 \mathrm{kG}$ を超えるが，これはテーパ 一により磁束が絞り込まれることによる.

次に, 励磁するコイルの位置の違いによる, ヘッド磁界の強さ の比較を行った. Fig.9 は，それぞれの位置に設置したコイルにつ

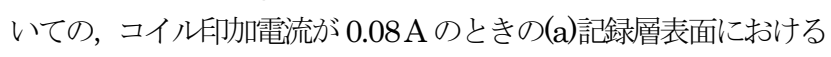
主磁極中心での磁界の值，および(b)磁界勾配の最大值を示してい る. Fig.9 はコイル位置を主磁極先端から測ったものを横軸として, 磁界および磁界勾配の值をプロットしたものである. 戻り磁路の 無い場合は，主磁極先端に近づけてコイルを設置したものほど， 強い磁界が得られる。一方，戻り磁路が有る場合は，コイルによ り励磁される部分がごの位置にあっても, 強く急峻な磁界が得ら れ，またコイル位置による磁界の違いは小さい，前述のとおり， 戻り磁路と SUL が作る磁気回路の効果とテーパーの絞込み効果 により, 主磁極先端の磁束密度が大きくなっているためである.

さらに, ヘッド磁界の広がり具合を確かめるために, 主磁極先 端に近い位置にコイルを置いた場合と，先端から離れた位置にコ イルを置いた場合とで, 磁界分布の比較を行った. Fig.10は, (a) ダウントラック方向，および(b)クロストラック方向の規格化され たヘッド磁界分布であり, 記録電流は $0.32 \mathrm{~A}$ と, 戻り磁路が有 るときのコイル位置 1 とコイル位置4の場合について示している. 磁界分布は, 両者の場合ともに, クロストラック方向およびダウ ントラックのトレーリングエッジ側の裙の広がりが大きいが，主 磁極先端に近いコイル位置 1 の場合の方が, 裾引きがより顕著で ある.この場合，隣接トラック信号を消去してしまうことが無い ように注意しなければならない。

また，戻り磁路が有り，コイルをヘッド磁路のループの外に設 置した場合（コイル位置2）についても解析を行った. コイル位 置 2 の場合, 主磁極からの距離は, コイル位置 1 と同じであるに もかかか氺らず, ヘッド磁界は $3.0 \mathrm{kOe}($ 印加電流 $0.08 \mathrm{~A})$ と, コ イル位置 1 の場合の $13.3 \mathrm{kOe}$ に比べて非常に小さい.これは次に 示寸とおり，戻り磁路も含んだ磁気回路全体とコイルの位置関係 によるものである. Fig. 11 は, 印加電流が $0.08 \mathrm{~A}$ のきのヘッド 周りの磁束密度ベクトル図であり，(a)がコイル位置1の場合を, (b)がコイル位置 2 の場合である. 主磁極先端での極性を一致させ るために, コイル位置 1 とコイル位置 2 に印加する電流の向きは 逆向きとなるように設定している. Fig.11(a)のように，コイル位 置1の場合では, コイルにより反時計回りの磁界が発生し、ヘッ (a)

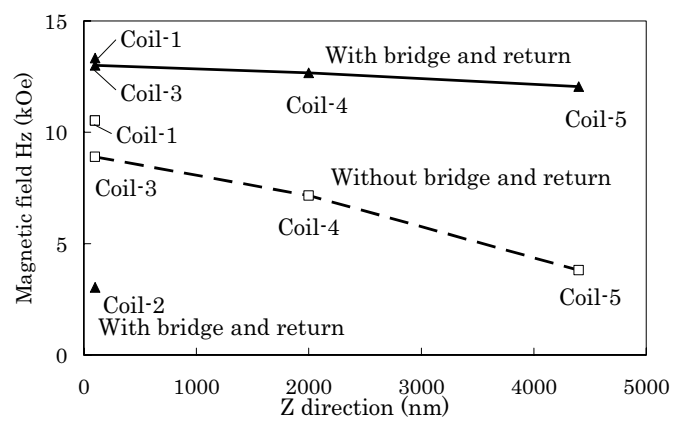

(b)

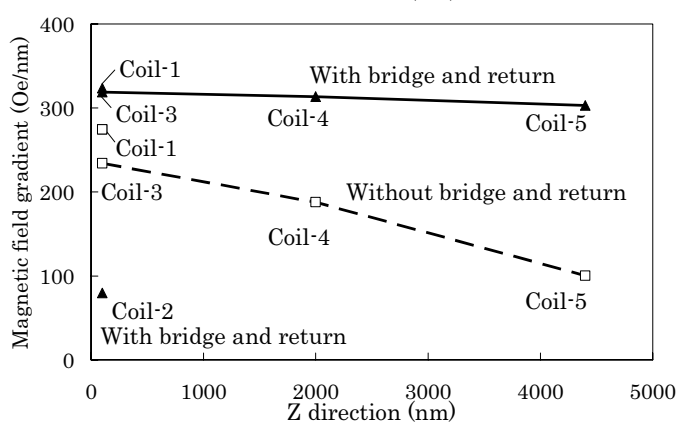

Fig. 9 (a) Magnetic field and (b) field gradients for a coil current of $0.08 \mathrm{~A}$, with a return yoke (filled triangle) and without a return yoke (white rectangle).

(a)

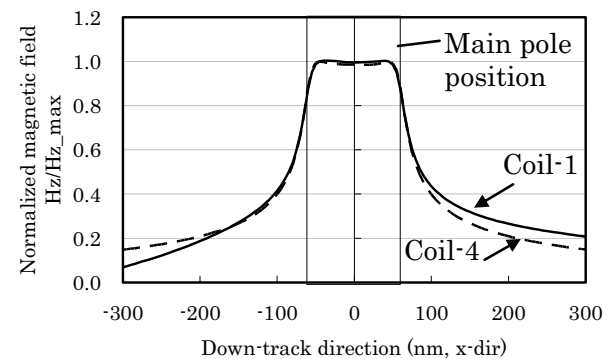

(b)

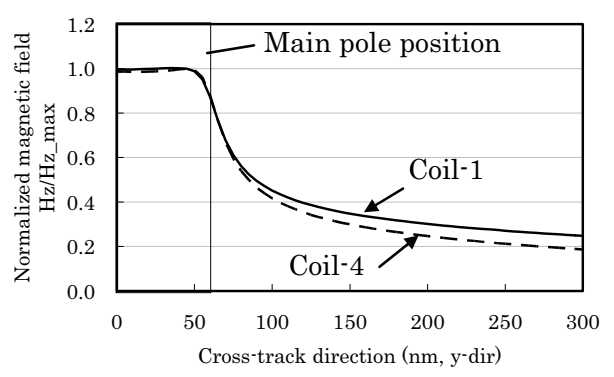

Fig. 10 Normalized magnetic field of the recording head in (a) the down-track direction, and (b) the cross-track direction in the case of coil- 1 (solid line) and coil-4 (dotted line).

(a)

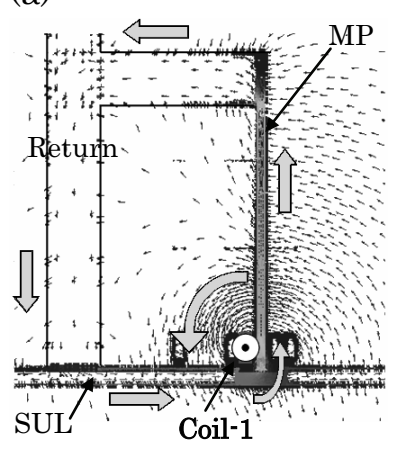

(b)

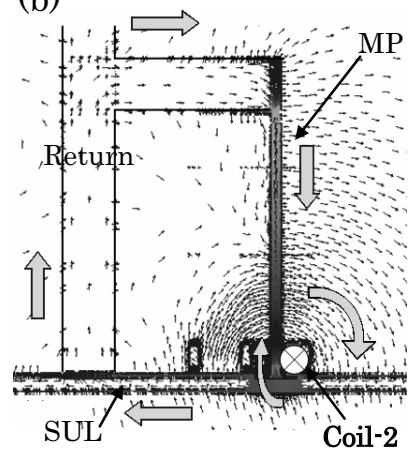

Fig. 11 Magnetic field vector around the head with the current of (a) coil-1 and (b) coil-2. 
ド磁路に対して反時計回りにそのまま作用する. したがって，へ ッド磁路内では，主磁極先端では上向きの，リターンヨークでは 下向きの磁束の流れとなる. これらにより磁路内には一方向の磁 束の流れが発生し, さらにテーパーの絞込み効果により, 主磁極 先端において磁束密度が大きくなる. これに対し, コイル位置 2 の場合では, Fig.11(b)に示されるように，主磁極先端は上向きに 励磁される. またリターンヨークも，コイル磁界により上向き励 磁される. ブリッジに接続した主磁極の上部ではリターンヨーク からの磁束により下向きの流れとなり, 主磁極先端とで反対向き の磁束の流れとなる. Fig.12 は, コイル位置 2 の場合で印加電流 が $0.08 \mathrm{~A}$ のきの, 主磁極中心軸での垂直方向磁束密度分布であ る. 主磁極内の磁束密度が, 主磁極の先端とブリッジ接続側とで 符号が反転している. このように，主磁極内で磁束が反転し打ち 消されるために, 励磁効率が悪くなる. ヘッドが戻り磁路の構造 を持つ場合，コイルが磁路のループを貫くかどうかにより，励磁 効率は大きく異なることがわかる.

\section{3 カスプ型ヘッドの検討}

カスプ型コイル 5)を用いた単磁極ヘッドでは, 主磁極の 両側にリターンヨークがある Double Yoke 構造の磁極と,

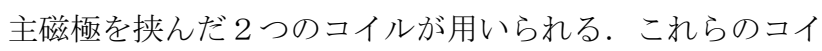
ルには，互いに逆向きの電流が印加される．これまで述べ てきた検討結果を, カスプ型構造ヘッドの特性の解析に活 用することを試みた. Fig.13(a)は，片側リターンヨークの もの(Single Yoke), Fig.13(b)は, 両側リターンョークのも の(Double Yoke)のヘッド側面図である.これらのへッド磁 界の印加電流依存性を Fig.14 に示す. グラフの横軸は, コ イルひとつあたりの電流をあらわし, Single Yoke の場合の コイル 1 のみまたはコイル 2 のみの電流を, およびコイル 1 とコイル 2 の両方に逆向きに電流を印加したもの, Double Yoke の場合のコイル1のみの電流を, およびコイ ル 1 とコイル 2 の両方に逆向きに電流を印加したものの磁 界依存性である。

まず Single Yoke の場合で, コイル 1 とコイル 2 の両方 に電流を印加した場合は, コイル 1 のみ電流を印加した場 合と比べて磁界の值はやや大きくなり, また磁界強度が飽 和した後の増大も著しくなる。また，コイル 2 のみの場合 は, 前述のとおり磁極内で磁束の流れが反転することによ り，磁界は弱く線形に増大寸るという結果が得られた。こ れらのことから，コイルの設置位置とともにへッドが作る 磁路との位置関係も, 記録磁界に大きな影響を与えている ことがわかる.

次に, Single Yoke から Double Yokeに変えた場合では, コイル 1 のみの場合は, 飽和磁界が大きく下がる.これは, 磁路を付け加えたことにより, リターンヨークから主磁極 に向から磁束が，主磁極側と付け加えたブリッジ・リター ンヨーク側とに分流してしまうためである. また, コイル $1+$ コイル 2 の 2 個のコイルがある場合は, 磁界依存性は Single Yokeでも Double Yoke でも変わらず, 磁路を付け 加えた影響はほとんど見られない. Fig.15 は, Double Yoke の場合とリターンヨークが無い場合とでコイル 1 とコイル

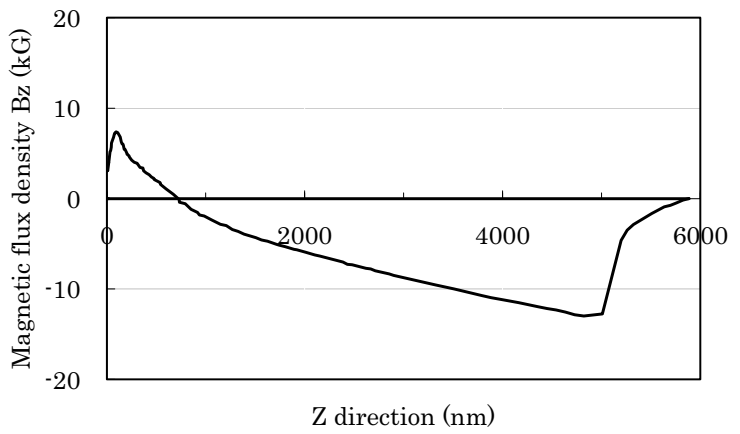

Fig. 12 Magnetic flux density in the main pole in the case of coil-2 with a return yoke.

(a)

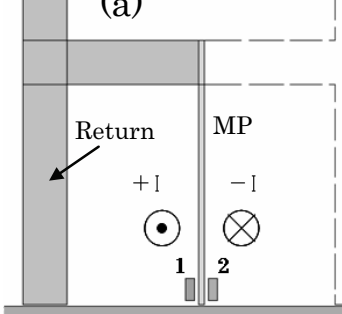

(b)

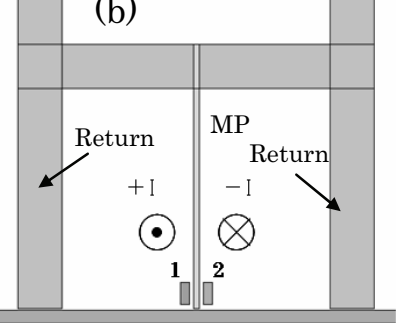

Fig. 13 Side view of (a) a single-yoke head, and (b) a double-yoke head.

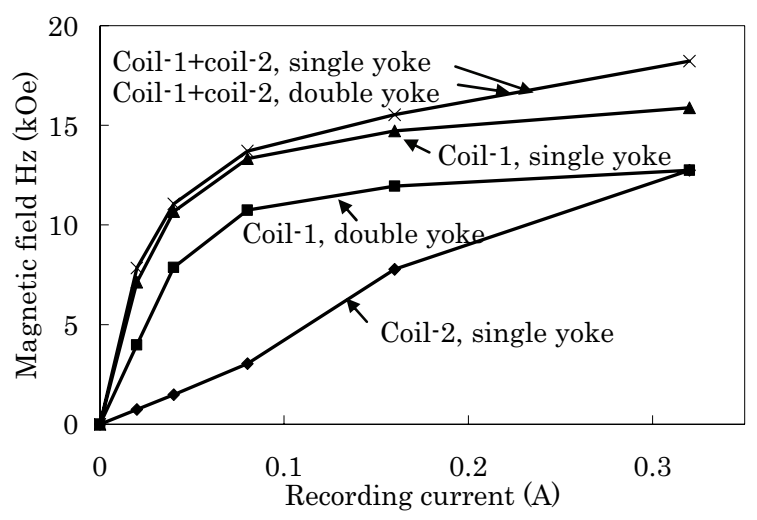

Fig. 14 Magnetic field dependence on the recording current in the case of a double yoke and a single yoke.

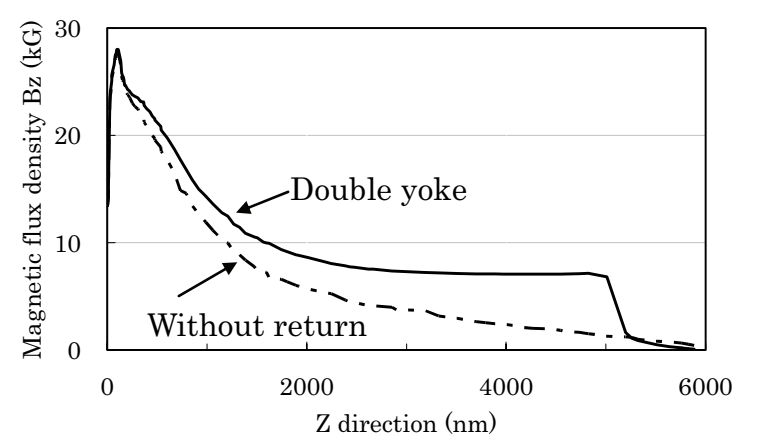

Fig. 15 Magnetic flux density in a main pole in the case of coil-1 and coil-2 of a double-yoke head (solid line) and without a return yoke head (dotted line).

2 に互いに逆向きに $0.08 \mathrm{~A}$ の電流を印加した場合の, 主磁 極中心軸での垂直方向磁束密度分布である. なお, Single Yoke の場合の磁界分布は, Double Yoke のものとほぼ一致して いた. Fig.8 と比べると, リターンヨークを持つ場合でも, 戻り 磁路からの磁束の流れ込みはそれほど大きくないことがわかる. 
このことは, リターンヨークから記録層への戻り磁界も小さいこ とを示寸.コイルとヘッドの構造からみると, コイルの挟む内側 では磁界の方向は一致し，また外側では磁界は逆極性となるため， コイル磁界が戻り磁路の磁束の流れに寄与寸る割合は小さ い. また, 戻り磁路の効果が得られなくても強いヘッド磁 界が得られた要因は，2つのコイルが主磁極先端に巻かれ ていることによるものである，すなわち，主磁極を挟むよ うにコイルを設置した場合には，コイルを主磁極先端に近 づけて設置することで強いヘッド磁界を得ることが出来る。

結果が示すように, カスプ型コイルを用いたヘッドに代 表されるような, Double Yoke 構造で主磁極先端を両側か ら励磁する構造は, 磁路の戻り磁界を抑え, かつ励磁効率 を劣化させずに強い記録磁界を得ることができることを示 している.

\section{4 ヘッド・媒体相互作用の影響}

記録過程の正確な解析においては, ヘッド・媒体相互作用を考 慮する必要がある. 有限要素法による電磁界計算において, ヘッ ド・媒体系を扱う場合には経験的に，記録層の透磁率を 2 程度と 想定して計算することもよく行われてきており，どのような透磁 率值を用いるべきかの議論もなされている10)。しかし，このよう な透磁率換算は，ひとつの近似にすぎず，媒体の磁化によってへ ッド磁界が修正されるようなへッド媒体相互作用を考慮すること ができない，そこで，前述のモデルに加えて記録層の磁化を含ん だモデルによる計算を行った. 計算条件は, 2.2 に示寸. Fig.16 は，コイル印加電流を変えたときの，記録層表面でのヘッ ド磁界分布である. (a)が記録層を考慮しない場合, (b)が記 録層を考慮して計算した場合の結果である。記録層を考慮 した場合には, ヘッドと媒体の相互作用により, 主磁極内 の減磁界が弱められ, 記録磁界が強まる。この効果は, 磁 界強度が未飽和である $20 \mathrm{~mA}$ の場合では, 約 1.2 倍である。 また, 磁界分布もより急峻になり, 最大磁界勾配が増加す る.これも $20 \mathrm{~mA}$ の場合で, 約 1.5 倍の効果となる.

記録層の磁化が作る磁界が主磁極先端の反磁界を弱める ように働くため, ヘッドの磁界強度は強まり, また磁界勾 配も増大寸る．媒体の磁気特性を最適化することにより， さらに強い書き込み磁界や勾配を得ることを期待できる.

\section{4. まとめ}

垂直磁気記録の単磁極へッドと, 軟磁性裏打ち層の系に 関する電磁界計算により, 強くかつ急峻な勾配の記録磁界 を発生するための条件を検討した。ヘッドと記録媒体の軟磁 性裏打ち層(SUL)が構成する磁気回路の効果により，小さな電流で も効率的に飽和寸るへッド磁界が得られることを確認し，その結 果, 次のことが明らかとなった.

（1）へッド磁極内部の磁束密度が大きくなる領域は，コ イルの設置位置により決定される，コイルを主磁極の先端 に巻くことで, より強い磁界が得られる.

（2）コイルの設置位置のみならず，リターンヨークの設 置方法などヘッドの磁路構造が記録磁界に与える影響も大 きい. 理想的には, 主磁極の先端に近い部分を励磁するこ
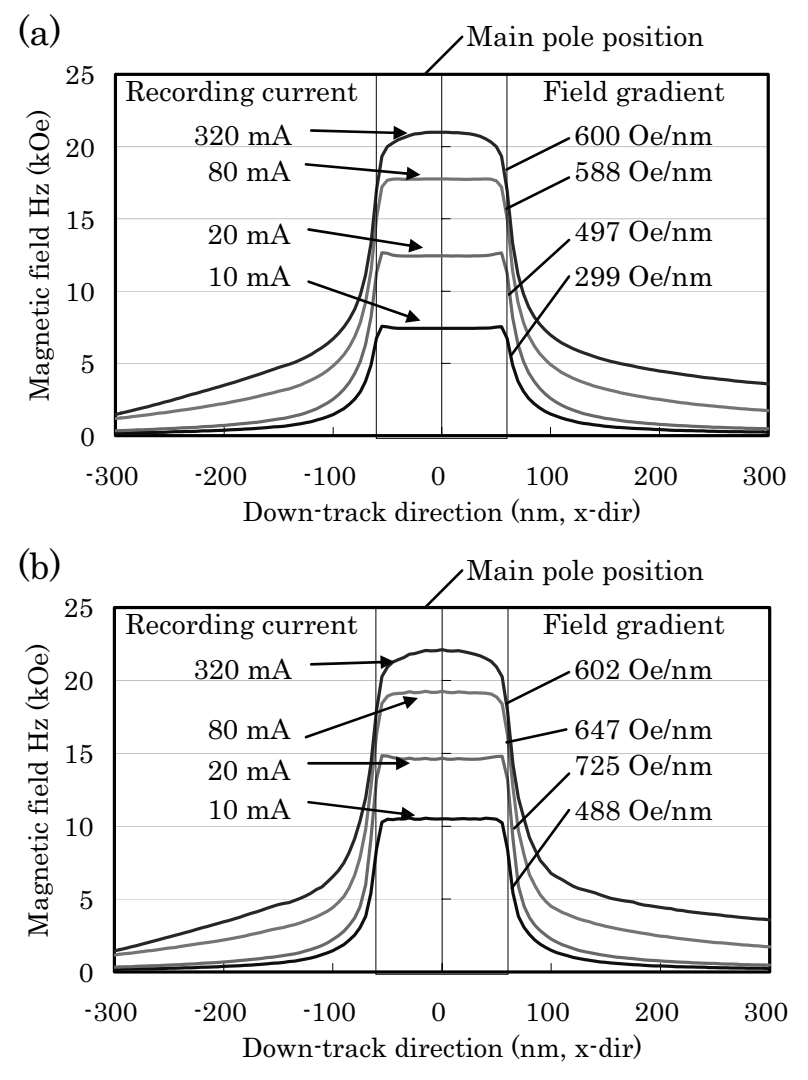

Fig. 16 Magnetic field distribution around the recording head in the case of (a) not calculating the recording layer, and (b) calculating the recording layer.

とが望ましいが,ヘッドと SULによる閉磁路構造がコイル による励磁作用を補完し，十分に強くかつ急峻な勾配の記 録磁界を得ることが出来る。

（3）ヘッド・媒体相互作用を考慮した記録過程の計算を 行った。媒体の記録層が存在することにより，ヘッド磁界 が強く, 磁界勾配が大きくなる効果がある.

謝辞 秋田県高度技術研究所の山川清志氏には本研究を行 うにあたり多大のご助言を頂いた。ここに感謝する。本研 究の一部は, SRCの支援を得て行った。謝意を表する.

\section{References}

1) Y.Nakamura, Magnetics Japan, 1, 489 (2006).

2) Y.Nakamura, Magnetics Japan, 2, 41 (2007).

3) Y.Nakamura and S.Iwasaki, IEEE Trans. Magn., MAG-23, 153 (1987)

4) Y.Nakamura and I.Tagawa, IEEE Trans. Magn., 25, 4159 (1989).

5) K.Ise, K.Yamakawa, K.Ouchi, H.Muraoka, Y.Sugita, and Y.Nakamura, IEEE Trans. Magn., 36, 2520 (2000)

6) http://www.jri.co.jp/pro-eng/jmag/jmg/ (As of March 30, 2007)

7) W.Xia, T.Yamada, H.Aoi, H.Muraoka, and Y.Nakamura, $J$. Magn. Magn. Mat., 287, 77 (2005)

8) E.H.Frei, S.Shtrikman and D.Treves, Phys. Rev., 106, 446 (1957).

9) A.Aharoni and S.Shtrikman, Phys. Rev., 109, 1522 (1958).

10) R.H.Victora, J.Xue, and M.Patwari, IEEE Trans. Magn., 38, 1886 (2002)

2007年3月31日受理，2007年5月16日採録 